\title{
Ventilation circuit for large and gassy longwall panels - an Australian perspective
}

\section{A. Halim*}

\begin{abstract}
The current trend in Australian longwall mines is to increase panel dimensions and production rate, and mining in gassy regions. However, this trend poses a challenge to provide adequate ventilation to manage gas emissions. While the traditional two heading gateroad bleederless $U$ ventilation circuit, which is the most commonly used circuit in Australia, is no longer suitable due to its low volumetric capacity, a few mines manage to overcome this problem by employing a three heading gateroad ventilation circuit. However, this circuit requires significant additional development, which makes it not popular in Australian coal mines. The aim of this paper is to review the suitability of two heading and three heading gateroad traditional bleederless $U$ ventilation circuits for a large longwall panel mining in gassy conditions. It was found that significant predrainage of the thickest roof seam is required in order to make the two heading gateroad circuit feasible in large and gassy longwall panels.
\end{abstract}

Keywords: SGE, Panel pressure, Face velocity, Gas drainage, Residual gas content, Ventsim Visual simulation

\section{Introduction}

The current trend in Australian longwall mines is to increase panel dimensions and production rate, and mining in gassy regions. The benefits of increasing the dimensions of a longwall panel are improved development ratios, fewer longwall moves, higher recovery and improved utilisation of face equipment (Moreby, 2009). However, this trend poses a challenge to provide adequate ventilation to manage gas emissions. The traditional two heading bleederless $U$ ventilation circuit, as shown in Fig. 1, is no longer suitable in some situations due to its low volumetric capacity. A few mines manage to overcome this problem by employing a three heading gateroad ventilation circuit.

A three heading gateroad ventilation circuit, as shown in Fig. 2, has been used in a few longwall operations in Australia in recent times. This ventilation circuit provides many advantages in term of the extra ventilation capacity, access and escapeway. However, it is not popular in the Australian coal mining industry. The main reason for this is the significant increase in development meterage required (Moreby, 2009). For this reason, the two heading circuit is still the preferred option. However, with the current trend of increasing longwall panel sizes (400 m width and 4-6 km length) and mining in gassy condition (depth of 350-400 m), the two heading circuit is becoming inadequate to manage high longwall gas emissions.

Department of Mining Engineering, Western Australian School of Mines, Curtin University, Locked Bag 30, Kalgoorlie, WA 6433, Australia

*Corresponding author, email A.Halim@curtin.edu.au
The aim of this paper is to review the suitability of two and three heading gateroad circuits in large and gassy seams suitable for longwall extraction.

\section{Methodology}

The study uses as an example a 4-6 km long longwall panel extracting at $375 \mathrm{~m}$ depth the Goonyella Middle (GM) seam in Queensland's Bowen Basin coalfield. This is based on a proposed mine that is currently under prefeasibility study. The first step of this study was to determine the longwall panel ventilation air requirement. This was achieved by modelling longwall gas emission to determine specific gas emission (SGE). The ventilation requirement was then calculated based on SGE, proposed average production rate, peak production factors and tailgate gas concentration limit.

The next step was determining whether goaf drainage will be required. The air velocity at the longwall face has a rule of thumb limit of $5 \mathrm{~m} \mathrm{~s}^{-1}$ to prevent dust pick up, and from the required ventilation quantity, it can be seen whether the corresponding air velocity exceeds the limit or not. If it exceeds the limit, goaf drainage is employed to reduce the ventilation requirement. Based on operational experience of existing mines that extract the GM seam, it has been found that the maximum achievable goaf drainage capture efficiency is $70 \%$. This capture efficiency was then used to determine the revised ventilation requirement.

Ventilation network simulations of two and three heading gateroad traditional bleederless $U$ circuits using Ventsim Visual software has been done to determine panel pressure requirements to achieve the revised ventilation requirement. The proposed extraction height is $4.2 \mathrm{~m}$ and two panel geometries have been simulated: 


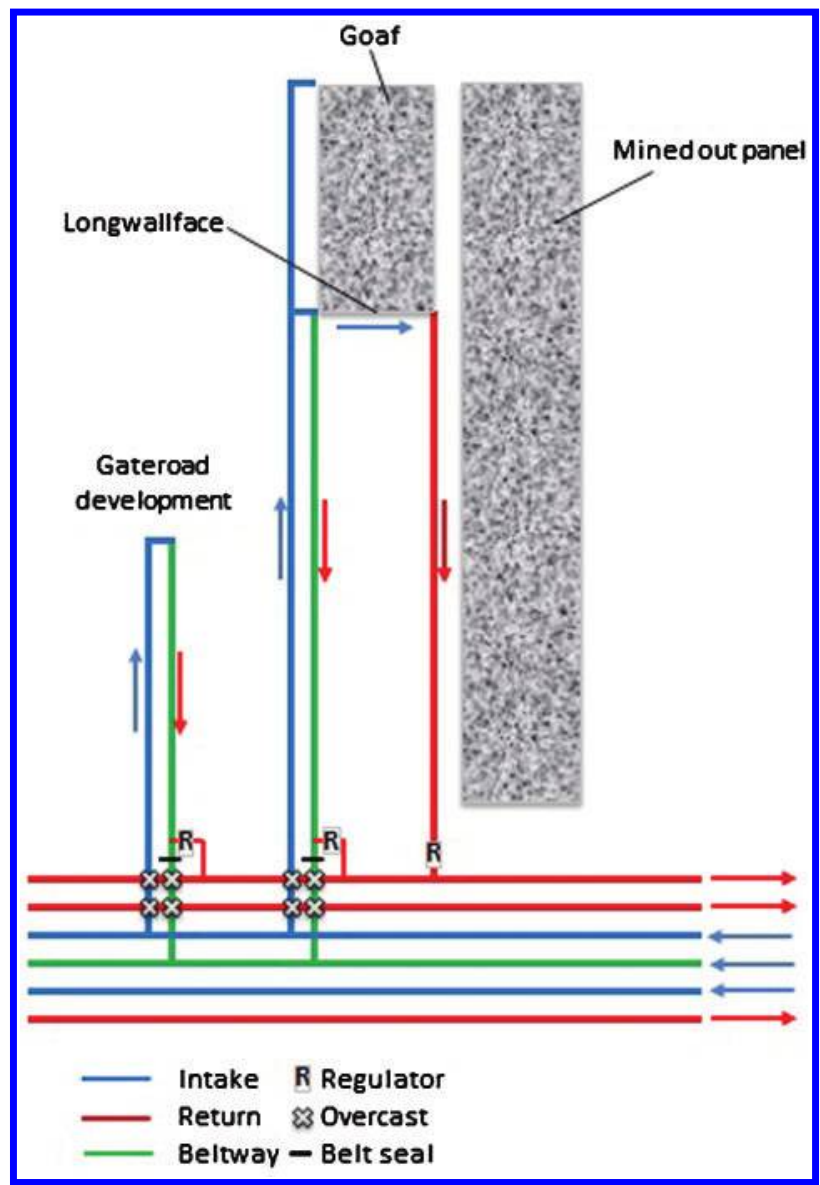

1 A typical two heading bleederless $U$ ventilation circuit

(i) $4 \mathrm{~km}$ long, $400 \mathrm{~m}$ wide panel

(ii) $6 \mathrm{~km}$ long, $400 \mathrm{~m}$ wide panel.

The airway properties such as friction factor and ventilation control device resistances were assigned based on values measured in selected Australian mines (Gillies and $\mathrm{Wu}, 2013$ ). It was assumed that the tailgate secondary structure support was installed before the panel start-up in order to avoid production delays. The resistance of this support was calculated using airway obstruction equation described in lecture note on underground mine environmental engineering (MEA, 2006a). The viabilities of two and three heading gateroad panels for this type of coal seam characteristic were determined from simulation exercises based on the ability of each ventilation circuit to achieve air requirements while maintaining minimum panel pressure and acceptable air velocity along the face.

The exercise was iterative and new strategies were tested if any of two and three heading circuits demanded excessive panel pressure or excessive face velocities to achieve ventilation requirements. Predrainage of one or more roof seams was examined in order to reduce SGE in exercises. From these steps, the most appropriate ventilation circuit for a large longwall block extracting coal within a gassy seam could be determined. The result of the exercise can be applicable in New South Wales mines or even mines in other countries, although the focus of this study was to a mine located in Queensland since gas emission is proportional to production rate and depth.

\section{Longwall gas modelling}

The stratigraphy of longwall panel is shown in Fig. 3.

The modified Flugge $58.5^{\circ}$ caving model was used to predict longwall SGE. The algorithm of this model is

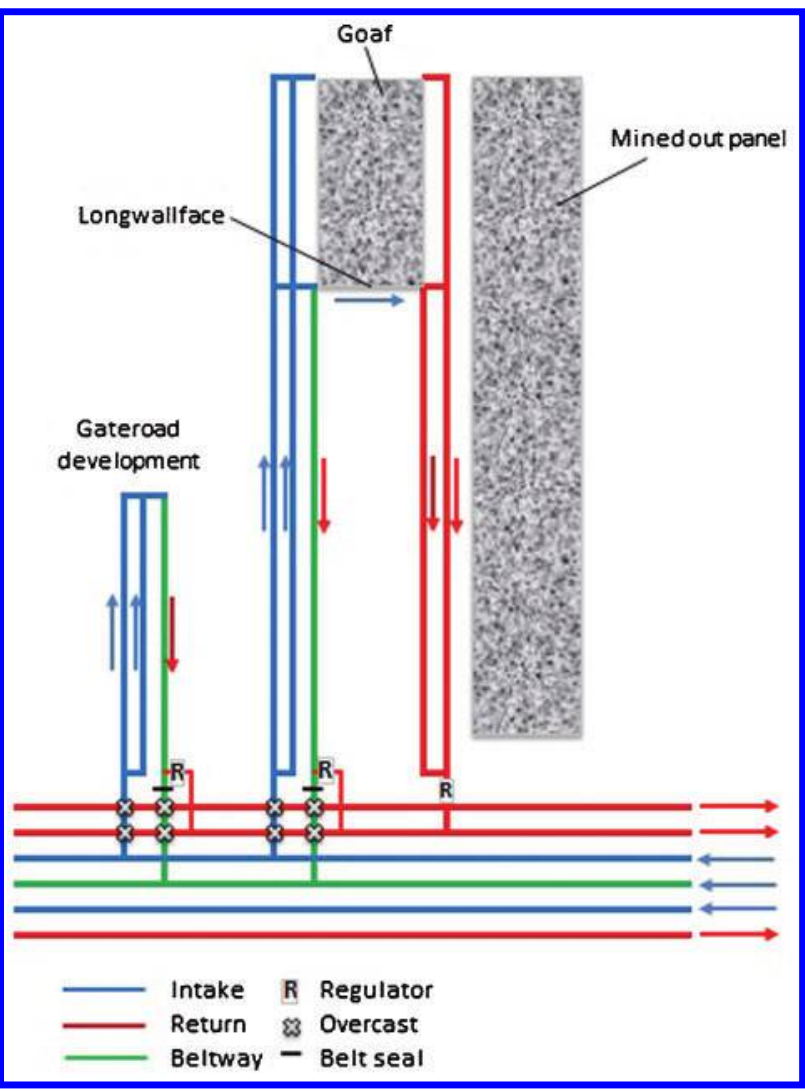

2 A typical three heading bleederless $U$ ventilation circuit

described in lecture note on underground mine environmental engineering (MEA, 2006b) and incorporated in an Excel spreadsheet created by Dr Roy Moreby for MEA. The original model was modified as it assumes that the whole caving zone is permeable and does not take into account the overburden movement and reconsolidation effect upon permeability, and residual gas content of seams affected by the caving. As a result, the model tends to overestimate SGE. Therefore, some

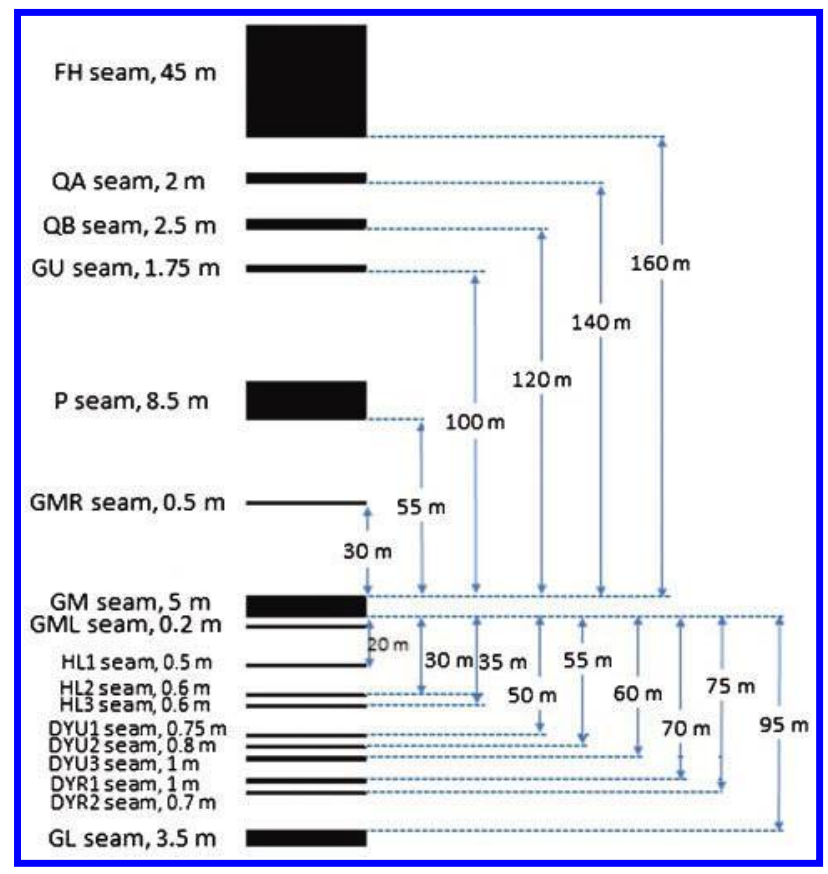

3 Coal seam thickness and proximity overview 


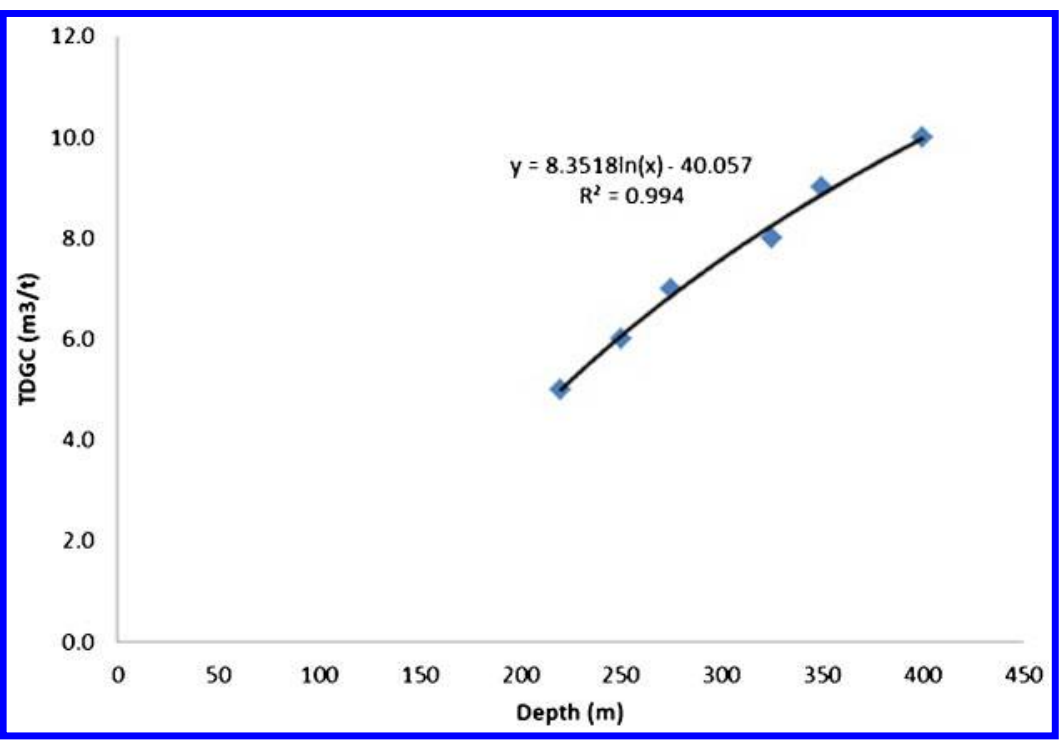

4 Total desorbable gas content versus depth relationship

modifications and assumptions were applied to the model:

1. The extent of the permeable zone in the caving zone is usually determined by geotechnical numerical modelling. However, as this model is not available, it was assumed that the zone is limited to 24 times extraction height into the roof and 14 times extraction height into the floor. This is the typical extent of a longwall caving zone (MEA, 2006b). With the proposed $4.2 \mathrm{~m}$ extraction height, this gives the area of influence of $101 \mathrm{~m}$ into the roof and $59 \mathrm{~m}$ into the floor. With the assumed permeable zone, only three roof seams (GU, P and GMR) and the unmined $0.8 \mathrm{~m}$ thick coal roof of the GM seam, and six floor seams (GML, HL1, HL2, HL3, DYU1 and DYU2) will contribute to the SGE (refer to Fig. 3).

2. In many cases (MEA, 2007), only working seam (GM seam) is sampled for measuring virgin gas content [total desorbable gas content (TDGC)], and this is the case in this study. Therefore, TDGC of other seams that contribute to SGE was determined from the GM seam's TDGC-depth relationship. This assumes that the relationship is the same for other seams that contribute to SGE.

3. Only $10 \%$ of GM seam gas contributes to the SGE. This is because it will take about $30-45 \mathrm{~min}$ for gas to be desorbed from the mined coal and by the time most of the gas is desorbed, the coal is no longer at the longwall face. It is already in the beltway or in the surface stockpile (MEA, 2006b).

4. The GM seam is predrained to $4 \mathrm{~m}^{3} \mathrm{t}^{-1}$. The main reason for this is that the TDGC of the GM seam at $375 \mathrm{~m}$ deep is higher than the Queensland's outburst threshold, which is $6 \mathrm{~m}^{3} \mathrm{t}^{-1}$. This predrainage is also required to reduce rib emission during the gateroad development.

5. Values from the study carried out by Moreby et al. (2010) were used for residual gas content of these seams.

\section{Reservoir characteristic}

Table 1 shows the typical TDGC of GM seam at various depths.

It can be seen from Table 1 that the TDGC increases with depth, which is the typical gas content-depth relationship. This is because gas particles are adsorbed onto coal particles and the degree of adsorption increases along with the groundwater pressure applied to the coal seam. The ground water pressure due to the higher hydrostatic head increases at depth.

\section{Estimation of TDGC in the longwall panel}

As the depth of the longwall panel is $375 \mathrm{~m}$, the TDGC of GM seam at that depth and of the other seams that will contribute to the SGE were estimated using a relationship between TDGC and depth from Table 1. The relationship is shown in Fig. 4.

Figure 4 shows that the relationship is

$$
\text { TDGC }=[8 \cdot 3518 \times \ln (\text { depth })]-40 \cdot 057
$$

The result can be seen in Table 2 .

\section{Result of longwall gas modelling and longwall ventilation requirement}

The gas modelling found that the total SGE for this longwall panel is $17 \cdot 4 \mathrm{~m}^{3} \mathrm{t}^{-1}$. This is within values observed in Australian mines (Moreby et al., 2010).

Table 1 Exploration core gas content data of GM seam

\begin{tabular}{lccc}
\hline Table exploration hole ID & Sample depth/m & TDGC/m $\mathbf{t}^{-\mathbf{1}}$ & Gas composition (\%CH $)$ \\
\hline 01 & 220 & $5 \cdot 0$ & 100 \\
02 & 250 & $6 \cdot 0$ & 100 \\
03 & 275 & $7 \cdot 0$ & 100 \\
04 & 325 & $8 \cdot 0$ & 100 \\
05 & 350 & $9 \cdot 0$ & 100 \\
06 & 400 & $10 \cdot 0$ & 100 \\
\hline
\end{tabular}


Table 2 Estimated TDGC of seams that contribute to SGE

\begin{tabular}{lll}
\hline Seam & Depth $/ \mathrm{m}$ & TDGC $/ \mathrm{m}^{\mathbf{3}} \mathbf{t}^{-\mathbf{1}}$ \\
\hline GU & 275 & $6 \cdot 8$ \\
P & 320 & $8 \cdot 1$ \\
GMR & 345 & $8 \cdot 7$ \\
GM & 375 & $9 \cdot 4$ \\
GML & 380 & $9 \cdot 6$ \\
HL1 & 395 & $9 \cdot 9$ \\
HL2 & 405 & $10 \cdot 1$ \\
HL3 & 410 & $10 \cdot 2$ \\
DYU1 & 425 & $10 \cdot 6$ \\
DYU2 & 430 & $10 \cdot 7$ \\
\hline
\end{tabular}

The ventilation requirement was determined based on SGE, average production rate of $150000 \mathrm{t} / \mathrm{week}$ on 7 days 24 hours continuous operation, and typical peak production rate factor of $1 \cdot 25$. The peak production rate factor was applied to take into account the cyclical nature of production at some stages of mining in which the production rate must be higher than the planned average rate. The longwall gas make was calculated as $5403 \mathrm{~L} \mathrm{~s}^{-1}$. It has to be noted that the ventilation air entering the face already contains a fraction of methane which is gained from rib emission in intake airways and cut coal in the beltway. The concentration varies but a typical value of $0 \cdot 15 \%$ methane can be assumed (Moreby, 2009). Therefore, the ventilation requirement to dilute the methane gas concentration to below $1 \%$ in the tailgate was calculated as $640 \mathrm{~m}^{3} \mathrm{~s}^{-1}$. Although the maximum methane gas concentration to trip power at the tailgate drive as prescribed by Queensland coal mine industry standards is $2 \%$, halving the limit is necessary to allow diesel equipment to enter the tailgate. This is because the industry standard states that diesel vehicles must be withdrawn from areas where methane concentration exceeds $1 \%$.

This requirement is not feasible as it will result in an air velocity at the face of $\sim 25 \mathrm{~m} \mathrm{~s}^{-1}$ based on longwall face cross-sectional dimension of $4.2 \mathrm{~m}$ high and $6 \mathrm{~m}$ wide. Therefore, goaf drainage would be required. Based on operational experience at mines that extract the GM seam, realistic goaf drainage capture efficiency is no more than $70 \%$. Therefore, the utilisation of $70 \%$ goaf drainage capture efficiency was used to determine the new ventilation requirement. It was found that with the utilisation of goaf drainage, the ventilation requirement was reduced significantly from 640 to $190 \mathrm{~m}^{3} \mathrm{~s}^{-1}$. The face velocity for this quantity is $7.5 \mathrm{~m} \mathrm{~s}^{-1}$. This value exceeds the rule of thumb limit of $5 \mathrm{~m} \mathrm{~s}^{-1}$ to prevent dust pick-up. However, with intense dust suppression systems such as the recently developed CSIRO's shearer scrubber (Ren et al., 2009) and intense water sprays, it can be argued that this velocity be acceptable. Thus, this air quantity was used in the longwall panel ventilation circuit simulations.

\section{Longwall panel ventilation circuit simulations}

A typical Australia longwall mine panel simplified ventilation circuit is shown in Fig. 5. Mine surveys carried out in seven gassy Queensland mines between 2003 and 2012 found that the longwall panel pressure comprises the largest portion of the total mine pressure loss (primary mine fan pressure) with this pressure ranging from 40 to $80 \%$ of the primary fan pressure (Gillies and $\mathrm{Wu}, 2013$ ). Therefore, the longwall panel pressure is a good indicator of the primary fan pressure. For this reason, only the longwall panel ventilation circuit has been simulated.

The simulation was done when the panel has retreated by $400 \mathrm{~m}$ as this is when the goaf drainage becomes fully effective with a fully formed goaf available. This situation usually occurs when the goaf footprint is square and the retreat is equal to the panel width. Ventilation is the principal means of gas management between longwall start-up and this point. Hence, the production rate must be slowed to $\sim 30 \%$ of the average planned production rate at this stage in order to allow panel gas emission to be manageable. This slow production rate is also necessary to control the formation of the goaf and to minimise the risk of windblast (MEA, 2006c).

The following airway friction factors and stopping resistances were applied in the simulation. These values are based on measurements from 13 mines in Queensland between 2003 and 2012 (Gillies and Wu, 2013):

(i) maingate travelway and tailgate: $0 \cdot 00817$ $\mathrm{N} \mathrm{s}^{2} \mathrm{~m}^{-4}$

(ii) maingate beltway: $0 \cdot 01137 \mathrm{~N} \mathrm{~s}^{2} \mathrm{~m}^{-4}$

(iii) longwall face: $0 \cdot 028 \mathrm{~N} \mathrm{~s}^{2} \mathrm{~m}^{-4}$

(iv) maingate stopping (14 kPa): $1200 \mathrm{~N} \mathrm{~s}^{2} \mathrm{~m}^{-8}$. It was assumed that the tailgate secondary support was installed before the panel start-up in order to avoid production delays. The support consists of $1 \cdot 1 \times 1 \cdot 1 \mathrm{~m}$ stacked timber crib pillars at $3 \mathrm{~m}$ centre to centre spacing. An airway obstructions equation (MEA, 2006a) can be used to calculate the resistance of this secondary support. It was found that the resistance per support is $0.0000798 \mathrm{~N} \mathrm{~s}^{2} \mathrm{~m}^{-8}$ and this value was applied in the simulations.

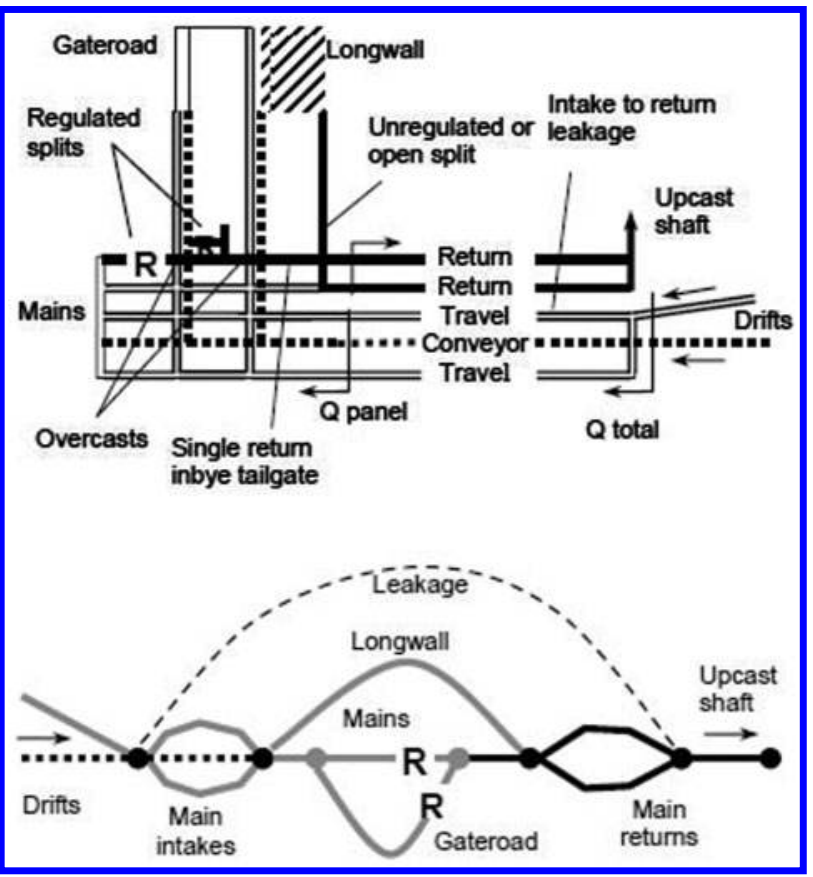

5 A typical Australian longwall mine ventilation circuit and its simplification (Moreby, 2009) 


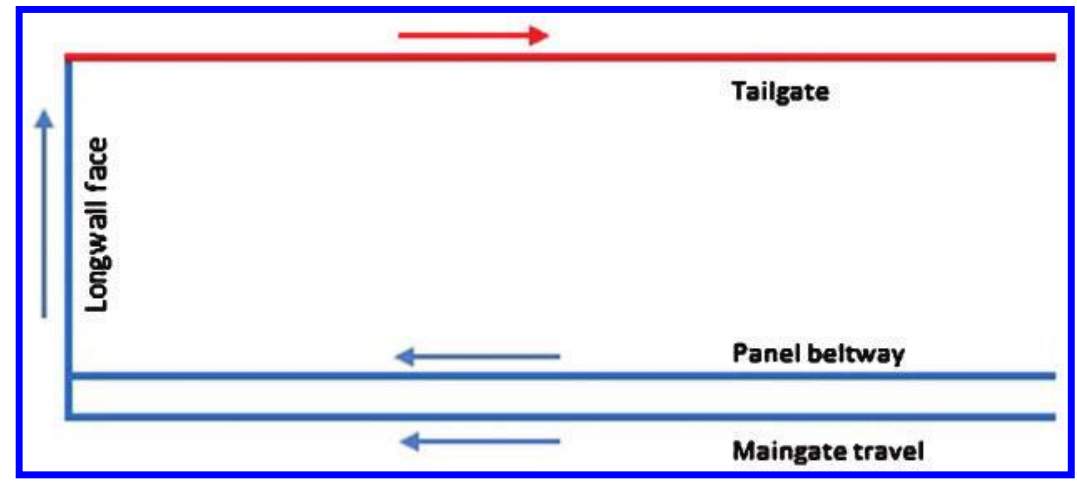

6 A two heading antitropal beltway circuit

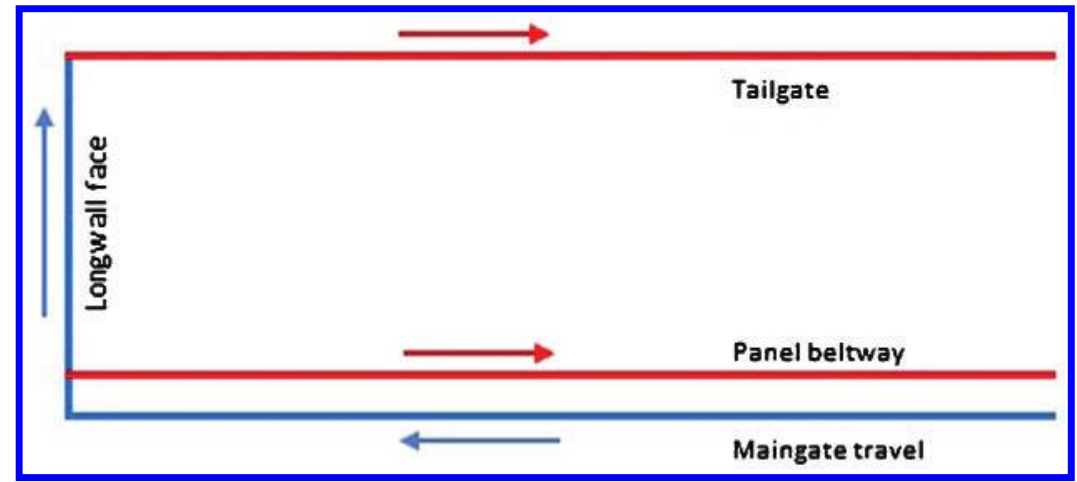

7 A two heading homotropal beltway circuit

\section{Simulation of two heading antitropal beltway circuits}

This circuit, as shown in Fig. 6, is the most commonly used longwall panel circuit in Australia. The beltway acts as an intake, hence the set-up is called antitropal, which means that the air flows in the opposite direction to the conveyor.

Table 3 shows the result of simulation of this circuit at 4 and $6 \mathrm{~km}$ panel lengths. Panel pressures for 4 and $6 \mathrm{~km}$ panel lengths were found to be 4.6 and $6.9 \mathrm{kPa}$ respectively. With these pressures, leakage across a well installed panel overcast with typical resistance of $900 \mathrm{~N} \mathrm{~s}^{2} \mathrm{~m}^{-8}$ would be $2 \cdot 3$ and $2 \cdot 8 \mathrm{~m}^{3} \mathrm{~s}^{-1}$ respectively, which is very high.

Assuming that the panel pressure is $70 \%$ of the primary fan pressure, these values correspond to primary fan pressures of 6.6 and $9.9 \mathrm{kPa}$ respectively. No installed coal mine primary fans in Australia have pressure around these values. To the author's knowledge, the largest coal mine primary fans that have been installed in Australia have pressure of $6.4 \mathrm{kPa}$ and from two $2400 \mathrm{~kW}$ centrifugal fans. This motor size is a very large one and significantly larger than the typical primary fan motor size of $450-1400 \mathrm{~kW}$. Therefore, with the primary fan pressure requirement of 6.6 and $9.9 \mathrm{kPa}$, the fan motor size would be significantly larger than $2400 \mathrm{~kW}$ and very expensive.

With the primary fan pressures mentioned above, the amount of leakage across mains outbye stoppings with typical resistance per stopping of $3500 \mathrm{~N} \mathrm{~s}^{2} \mathrm{~m}^{-8}$ will be 1.4 and $1.7 \mathrm{~m}^{3} \mathrm{~s}^{-1}$ per stopping. These values are very high.

\section{Simulation of two heading homotropal beltway circuits}

Mines in Queensland usually change from the antitropal beltway circuit to homotropal beltway (air flows in the same direction as the conveyor, thus acts as a return) during summer to prevent heat from the conveyor and cut coal passing to the longwall face. This circuit, as shown in Fig. 7, is the most commonly used longwall panel circuit in Queensland during summer. In addition to preventing heat from the conveyor and cut coal passing onto the face, another advantage of this circuit is

Table 3 Result of simulation of two heading antitropal beltway circuits

\begin{tabular}{|c|c|c|c|}
\hline Panel length/km & Face quantity $/ \mathrm{m}^{3} \mathrm{~s}^{-1}$ & Panel pressure/kPa & Face velocity/m s $\mathrm{s}^{-1}$ \\
\hline 4 & 190 & $4 \cdot 6$ & $7 \cdot 5$ \\
\hline 6 & 191 & $6 \cdot 9$ & $7 \cdot 6$ \\
\hline
\end{tabular}

Table 4 Result of simulation of two heading homotropal beltway circuits

\begin{tabular}{|c|c|c|c|}
\hline Panel length/km & Face quantity $/ \mathrm{m}^{3} \mathrm{~s}^{-1}$ & Panel pressure/kPa & Face velocity/m s ${ }^{-1}$ \\
\hline 4 & 190 & $6 \cdot 6$ & $7 \cdot 5$ \\
\hline 6 & 190 & $10 \cdot 4$ & $7 \cdot 5$ \\
\hline
\end{tabular}




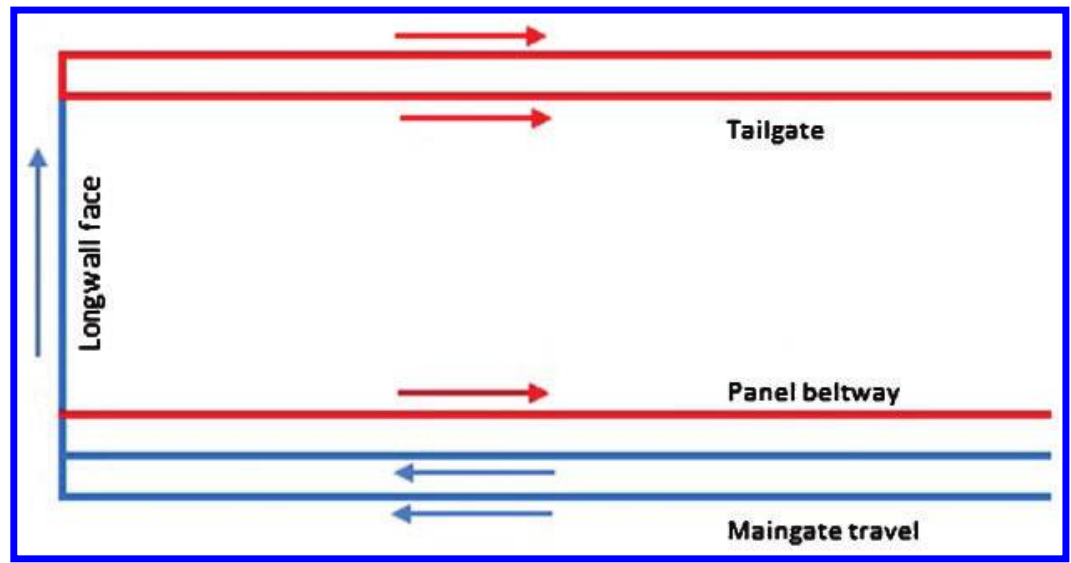

8 A three heading homotropal beltway circuit

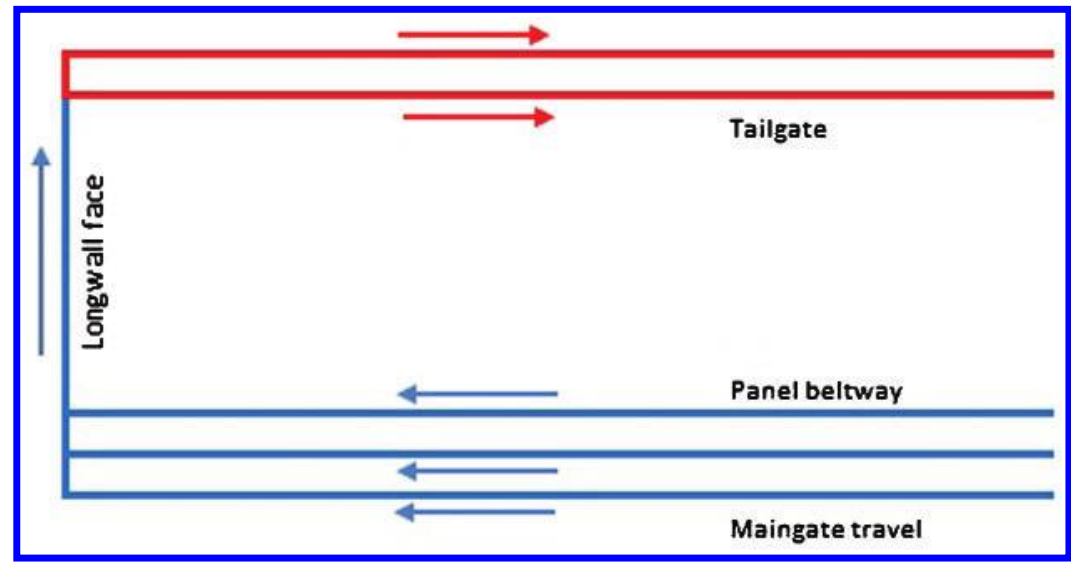

9 A three heading antitropal beltway circuit

preventing dust and gas from cut coal flowing onto the face. Table 4 shows the result of the simulations of this circuit. The panel pressure increases significantly than that in the antitropal circuit as there is only one intake (maingate travelway) and one return (tailgate). The tailgate is the bottleneck since it has the highest resistance due to secondary timber supports. The panel pressure, primary fan pressure and leakage issues related to this circuit are similar with those in the antitropal circuit, except to a more severe degree. With panel pressure of 6.6 and $10.4 \mathrm{kPa}$ respectively, the leakage and the primary fan pressure are significantly higher than those in an antitropal circuit.

\section{Simulation of three heading circuits}

As shown in Fig. 8, the main advantage of a three heading circuit is that the panel has two intakes (maingate travelways) and two returns (twin tailgate heading) and a homotropal beltway. The panel resistance decreases significantly as the total resistance of two parallel identical airways is a quarter of that of a single airway. In addition to this, an additional escape route is provided in both maingate and tailgate.

In New South Wales mines where heat is relatively not such an issue, the beltway can be made antitropal as shown in Fig. 9. This will further reduce the panel resistance as it now has three intakes. The same set-up can be done in Queensland mines during winter.

Table 5 shows the result of simulations of this circuit with homotropal beltway. The secondary support is installed in B heading as this is the roadway that is subjected to abutment pressure from the mined out and the active panels. It can be seen that the panel pressure decreases significantly from that in the two heading circuit. The panel pressure of $2.0 \mathrm{kPa}$ for a $4 \mathrm{~km}$ panel length is $30 \%$ of that of the two heading homotropal circuit and

Table 5 Result of simulation of three heading homotropal beltway circuits

\begin{tabular}{llll}
\hline Panel length/km & Face quantity/m $\mathbf{s}^{\mathbf{1}}$ & Panel pressure/kPa & Face velocity/m s \\
\hline 4 & 192 & $2 \cdot 0$ & $7 \cdot 6$ \\
6 & 191 & $2 \cdot 7$ & $7 \cdot 6$ \\
\hline
\end{tabular}

Table 6 Result of simulation of three heading antitropal beltway circuits

\begin{tabular}{lccc}
\hline Panel length/km & Face quantity $/ \mathrm{m}^{\mathbf{3}} \mathbf{s}^{-\mathbf{1}}$ & Panel pressure/kPa & Face velocity/m s $^{-1}$ \\
\hline 4 & 190 & 1.5 & 7.5 \\
6 & 191 & 2.0 & 7.5 \\
\hline
\end{tabular}


$43 \%$ of that of the two heading antitropal circuit. The panel pressure of $2.7 \mathrm{kPa}$ for $6 \mathrm{~km}$ panel length is $26 \%$ of that of the two heading homotropal circuit and 39\% of that of the two heading antitropal circuit.

Table 6 shows the result of simulations of this circuit with antitropal beltway. It can be seen that the panel pressure decreases from that in the homotropal circuit as the circuit now has three intakes. The reduction is $0.5 \mathrm{kPa}$ for $4 \mathrm{~km}$ panel length and $0.7 \mathrm{kPa}$ for $6 \mathrm{~km}$ panel length.

\section{Discussion}

It can be seen that the two heading circuit is not feasible as the panel pressure is excessively high and the corresponding primary fan pressure is not practically achievable. The two heading homotropal circuit has the highest pressure as it has the highest resistance due to one intake and one return.

A three heading circuit provides a major advantage in term of very significant panel pressure reduction compared with a two heading circuit. This leads to a significant reduction in leakage and primary fan pressure requirement. Assuming that the panel pressure is $70 \%$ of the primary fan pressure, the fan primary pressure for 4 and $6 \mathrm{~km}$ homotropal circuits would be 2.9 and $3.9 \mathrm{kPa}$ respectively. For antitropal circuits, the primary fan pressure would be 2.2 and $2.9 \mathrm{kPa}$ for 4 and $6 \mathrm{~km}$ panel lengths respectively. These pressures are within the typical range of Australian coal mines primary fan pressure. However, as described before, the main disadvantage of this circuit is the significant increase in development meterage required and thus development cost.

The only way to make a two heading circuit feasible is to reduce the ventilation requirement. To do this, it is obvious that SGE must be reduced. The only way to reduce SGE in this situation is the predrainage of one or more roof seam. Therefore, another gas modelling exercise was undertaken to include this scenario. In this modelling, the roof seam that was chosen to be predrained is $\mathrm{P}$ seam since it is the thickest seam and thus contributes the largest proportion of SGE. Results of this modelling show that with $\mathrm{P}$ seam predrained to $3 \mathrm{~m}^{3} \mathrm{t}^{-1}$, SGE was reduced significantly from $17 \cdot 4$ to $8.9 \mathrm{~m}^{3} \mathrm{t}^{-1}$. The longwall gas make was reduced from 5403 to $2747 \mathrm{~L} \mathrm{~s}^{-1}$ and the ventilation requirement was reduced from 190 to $97 \mathrm{~m}^{3} \mathrm{~s}^{-1}$. This requirement also causes face velocity to decrease to $3.9 \mathrm{~m} \mathrm{~s}^{-1}$, which is below the rule of thumb limit of $5 \mathrm{~m} \mathrm{~s}^{-1}$. Ventsim Visual simulations were repeated to include this new ventilation requirement. Tables $7-10$ show the results.

It can be seen from Tables 7-10 that the panel pressure in all circuits decreases significantly from the previous ones. The two heading circuits are now becoming more feasible as the panel pressure has been reduced to below $3 \mathrm{kPa}$.

Another modelling exercise was done in which $\mathrm{P}$ seam was predrained to below its residual gas content so that it does not contribute to SGE. It was found that SGE was reduced from 8.9 to $5.7 \mathrm{~m}^{3} \mathrm{t}^{-1}$, the longwall gas make was reduced from 2747 to $1769 \mathrm{~L} \mathrm{~s}^{-1}$ and ventilation requirement was reduced from 97 to $62 \mathrm{~m}^{3} \mathrm{~s}^{-1}$. With this requirement, panel pressure for two heading homotropal beltway circuits was reduced from 1.8 and $2.8 \mathrm{kPa}$ to 0.75 and $1.2 \mathrm{kPa}$ for 4 and $6 \mathrm{~km}$ panel lengths respectively.

\section{Conclusions}

A three heading circuit has a major advantage over a two heading circuit in terms of significantly less panel

Table 7 Result of simulation of two heading antitropal beltway circuits with P seam predrained to $3 \mathrm{~m}^{3} \mathrm{t}^{-1}$

\begin{tabular}{llll}
\hline Panel length $(\mathrm{km})$ & Face quantity $\left(\mathrm{m}^{\mathbf{3}} \mathbf{s}^{-\mathbf{1}}\right)$ & Panel pressure $(\mathrm{kPa})$ & Face velocity $\left(\mathrm{m} \mathrm{s}^{-1}\right)$ \\
\hline 4 & 97 & 1.2 & 3.9 \\
6 & 97 & 1.8 & 3.9 \\
\hline
\end{tabular}

Table 8 Result of simulation of two heading homotropal beltway circuits with $P$ seam pre-drained to $3 \mathrm{~m}^{3} \mathrm{t}^{-1}$

\begin{tabular}{llll}
\hline Panel length/km & Face quantity $/ \mathrm{m}^{\mathbf{3}} \mathbf{s}^{-\mathbf{1}}$ & Panel pressure $/ \mathrm{kPa}$ & ${\text { Face velocity } / \mathrm{m} \mathrm{s}^{-\mathbf{1}}}$ \\
\hline 4 & 97 & 1.8 & 3.9 \\
6 & 97 & $2 \cdot 8$ & 3.9 \\
\hline
\end{tabular}

Table 9 Result of simulation of three heading homotropal beltway circuits with $P$ seam predrained to $3 \mathrm{~m}^{3} \mathrm{t}^{-1}$

\begin{tabular}{llll}
\hline Panel length/km & Face quantity $/ \mathrm{m}^{\mathbf{3}} \mathrm{s}^{-\mathbf{1}}$ & Panel pressure $/ \mathrm{kPa}$ & Face velocity $/ \mathrm{m} \mathrm{s}^{-\mathbf{1}}$ \\
\hline 4 & 97 & 0.52 & 3.9 \\
6 & 97 & 0.74 & 3.9 \\
\hline
\end{tabular}

Table 10 Result of simulation of three heading antitropal beltway circuits with $P$ seam predrained to $3 \mathrm{~m}^{3} \mathrm{t}^{-1}$

\begin{tabular}{|c|c|c|c|}
\hline Panel length/km & Face quantity $/ \mathrm{m}^{3} \mathrm{~s}^{-1}$ & Panel pressure/kPa & Face velocity/m s $\mathrm{s}^{-1}$ \\
\hline 4 & 97 & 0.39 & 3.9 \\
\hline 6 & 97 & 0.52 & 3.9 \\
\hline
\end{tabular}


pressure requirement to deliver the same face quantity. This means that it has significantly more volumetric capacity over a two heading circuit, which is ideal in a large and gassy longwall panel. However, the main disadvantage is the significant additional development meterage requirement, and therefore significant additional development cost. This is the main reason why this circuit is not popular in Australia.

In order to make the two heading circuit feasible in large and gassy panels, significant predrainage of the thickest roof seam is required in order to reduce SGE. The amount of reduction depends on the amount of predrainage. When this seam is predrained to below its residual gas content, SGE is reduced very significantly as this seam no longer contributes to SGE. The caveat is that there is a significant capital and operating cost that will be incurred. The operating cost increases along with the amount of predrainage. However, with the requirement to reduce greenhouse gas emission from the primary fan in order to minimise the amount of carbon tax that has to be paid and potential commercialisation of coal seam gas, the capital and operating cost associated with predraining a roof seam might be justifiable. An optimisation study to gain an understanding of the balance between longwall panel ventilation and gas drainage to manage longwall gas emission should be carried out in the future.

\section{Acknowledgements}

The author wishes to acknowledge Australian coal mines' personnel who have provided data used in this study.

\section{References}

Gillies, A. D. S. and Wu, H. W. 2013. Unpublished work.

Mining Education Australia (MEA). 2006a. Lecture note on underground mine environment course, Module $1 \cdot 1$ Fluid flow, friction and shock losses.

Mining Education Australia (MEA). 2006b. Lecture note on underground mine environment course, Module 5.1 Gas reservoir characteristics.

Mining Education Australia (MEA). 2006c. Lecture note on underground mine environment course, Module 5.2 Gas drainage, outbursts and windblasts.

Mining Education Australia (MEA). 2007. Assignment note on underground mine environment course, coal mine hazards and ventilation design.

Moreby, R. 2009. Ventilation. In 'Monograph 12 Australasian coal mining practice', (ed. R. J. Kininmonth and E. Y. Baafi), 3rd edn, 604-814, Melbourne, The Australasian Institute of Mining and Metallurgy (AusIMM).

Moreby, R., Balusu, R., Yarlagadda, S., Ren, T. and Su, S. 2010. Strategic review of gas management options for reduced GHG emissions, Report C17057, Australian Coal Association Research Program (ACARP), Brisbane, Australia.

Ren, T., Balusu, R. and Plush, B. 2009. Dust control technologies for longwall faces - Shearer scrubber development and field trials, Report C14036, Australian Coal Association Research Program (ACARP), Brisbane, Australia. 